\title{
Com o rosário na mão: as entidades femininas e a legitimação do golpe de 1964 e da ditadura militar
}

Edison Lucas Fabrício

Mestrando em História (Universidade Federal de Santa Catarina - UFSC)

edisonlucasf@hotmail.com

CORDEIRO, Janaína Martins. Direitas em movimento: a Campanha da Mulher pela Democracia e a Ditadura no Brasil. Rio de Janeiro. Editora FGV. 2009. p. 202.

Originais recebidos em: 07/02/2011

Aceito da publicação em: 30/03/2011

\section{(1) $(1) \Theta \Theta$} Atribuição-Uso Não-Comercial-Vedada a criação de obras derivadas 3.0 Unported License.

Nos últimos anos produziu-se uma rica bibliografia sobre o contexto do Golpe de 1964 e os anos subseqüentes. Embora haja uma produção historiográfica bastante significativa, e os trabalhos acadêmicos certamente ocupam um lugar de destaque, há também muitos temas que ainda não receberam a devida atenção dos pesquisadores ou foram abordados de forma superficial. Um destes temas diz respeito à participação da sociedade, ou de parcelas significativas dela, na construção da ditadura militar.

O livro Direitas em movimento, de Janaína Martins Cordeiro é uma contribuição para a reflexão em torno da participação das entidades femininas na legitimação do Golpe de 1964 e do apoio ao regime militar. Janaina Cordeiro é Mestre em História pela Universidade Federal Fluminense e doutoranda pela mesma instituição. A obra que ora apresentamos foi originalmente escrito como uma dissertação de mestrado, sob o título "A nação um que se salvou a si mesma: entre memória e história, a campanha da mulher pela 
democracia 1962-1974". O trabalho foi vencedor do Prêmio PRONEX (Programa Nacional de Núcleos de Excelência - CNPQ), que viabilizou a publicação em forma de livro.

Já no prefácio, Denise Rollemberg, a orientadora da dissertação, nos adverte que muito tem se escrito sobre a resistência à ditadura no Brasil, todavia poucos pesquisadores se debruçaram sobre a questão do apoio civil ao golpe militar ou mesmo do papel dos civis à construção da ditadura. Na contracorrente das interpretações, alguns historiadores têm procurado enfatizar a ditadura como uma construção social. Uma vez que a ditadura não esteve desvinculada da sociedade, ela se impôs com um consenso e mesmo com o consentimento civil. Segundo Rollemberg a história da ditadura tem sido contada por uma linha interpretativa que exalta a resistência ao regime e ao mesmo tempo, vitimiza a sociedade.

$\mathrm{Na}$ introdução Janaína Martins Cordeiro assinala que ao longo dos anos 80, quando se iniciou o processo de redemocratização, começaram as sucessivas reconstruções de memória sobre o golpe e o regime militar. Em geral, prevaleceu uma memória ancorada no mito da resistência, segundo a qual toda a sociedade havia resistido à ditadura. Nesta perspectiva, a ditadura foi imposta de cima para baixo contra a vontade de todos. Todavia, entendemos que a história não pode ser simplificada binariamente, opondo ditadores de um lado e "democratas" de outro. Nesta reconstrução de memória as esquerdas foram vitimizadas e a luta armada tornou-se um segmento radicalizado da resistência democrática, sem um projeto de subversão da ordem vigente.

Neste ponto vale acrescentar a contribuição de Marcelo Ridenti, pois ele lança luz sobre a questão levantada por Janaina Cordeiro. Para Ridenti, é inadequado usar o termo "resistência" para qualificar alguns setores da esquerda armada brasileira, uma vez que o termo resistência é utilizado num sentido defensivo e não ativo ou ofensivo. O uso do termo ainda se torna mais problemático quando se adota o adjetivo democrático, "resistência democrática". Pois, as esquerdas não propunham uma simples volta à democracia nos moldes pré-64. Por outro lado, como afirma Daniel Aarão Reis, as esquerdas "não eram de modo nenhum apaixonadas pela democracia", assim como a direita. Mas é preciso assinalar que muitos ex-guerrilheiros se apropriaram do discurso da resistência democrática para legitimar suas posições nos governos democráticos posteriores a 1985. Para Ridenti neste ponto mora a mistificação, pois tal discurso é uma construção à 
posteriori, que justifica as posições políticas adotadas no presente. Ele assinala que é mais adequado utilizar o termo resistência sem o qualificativo democrática. (Ridenti, 2004, p. $53-66)$.

Já Janaína Cordeiro, para pensar a memória da colaboração ao regime, busca se apropriar de reflexões de autores europeus sobre regimes autoritários, principalmente de historiadores franceses que escreveram sobre a construção de memórias sobre a resistência a Vichy durante a ocupação nazista ou mesmo da construção de memórias dos alemães em relação ao nazismo (Pierre Laborie, Andreas Huyssen, Henry Rousso, etc). Todavia, guarda as devidas proporções e especificidades históricas dos casos europeus em relação à construção da memória da ditadura militar no Brasil a partir dos anos 80 .

Para a autora, um dos pontos fundamentais da construção da memória sobre o golpe e o regime militar é a edificação do "mito da sociedade resistente". Este mito silencia o fato de a ditadura "não se ter estabelecido unicamente por meio de instrumentos repressivos, mas, ao contrário, ter sido produto de parcelas significativas da sociedade e, em certa medida, uma demanda destas". (Cordeiro, 2009, p. 23). Todavia, nos momentos em que se arquitetava a transição para um governo civil, os próprios militares trataram de construir uma narrativa que dividia a responsabilidade do golpe e do regime militar com os grupos civis. Durante o governo Geisel foi reeditado pela Biblioteca do Exército o panfleto "A nação que se salvou a si mesma", publicado originalmente em forma de reportagem em dezembro de 1964 pela revista Seleções. A reportagem buscava contar a história de um povo que se rebelou e impediu os comunistas de tomarem conta de seu país. A edição de 1978 pretendia comemorar o $14^{\circ}$ aniversário da "Revolução" e lembrar que os militares não foram os únicos protagonistas, mas que os líderes da classe média, os empresários, a imprensa e as mulheres também tiveram um papel destacado na implantação e na legitimação do regime militar.

As mulheres da elite e da classe média adentraram ao cenário político na primeira década de 1960, elas organizavam-se em grupos nas principais cidades e realizavam um papel de mobilização da opinião pública contra o comunismo e em defesa dos valores cristãos e da família. O objetivo principal de Janaína Cordeiro é compreender a trajetória e a memória das militantes de um desses grupos: a Campanha da Mulher pela Democracia (CAMDE), fundada em 1962 por um grupo de mulheres católicas no Rio de Janeiro. A 
partir deste grupo a autora tenta entender o regime instaurado em 1964 como uma construção social, ou seja, como algo que só pode ser compreendido se levado em conta o consentimento e mesmo o consenso dos grupos civis em torno da legitimidade da intervenção militar naquele processo histórico.

No primeiro capítulo, "a mulher brasileira está nas trincheiras”, a autora descreve o surgimento da CAMDE e sua atuação política. A CAMDE não foi uma entidade isolada, no mesmo contexto surgiram várias outras organizações femininas em vários estados da federação. Em São Paulo foi fundada a primeira entidade, a União Cívica Feminina (UCF), em Belo Horizonte a Liga da Mulher Democrática (LIMDE), em Recife a Cruzada Democrática Feminina (CDF) e no Rio Grande do Sul a Ação Democrática Feminina Gaúcha (ADFG).

Segundo Janaina Cordeiro, a CAMDE surgiu em junho de 1962 na casa da professora aposentada Amélia Molina Bastos. Além das mulheres presentes na fundação da entidade, havia também três homens: o general Antonio de Mendonça Molina; o engenheiro e economista Glycon de Paiva e frei Leovigildo Balestieri (Cordeiro, 2009, p. 46). Todavia, Solange de Deus Simões assinala que houve pelo menos três versões da fundação da CAMDE, sendo que há divergências quanto aos detalhes de quem teria convocada a reunião, mas em linhas gerais há concordância nas narrativas quanto o local e as pessoas reunidas (Simões, 1985, p. 29).

Uma das atividades iniciais da entidade foi publicar manifestos condenando a política exterior do Itamaraty que buscava reatar relações com a União Soviética. Neste sentido, o jornal $O$ Globo se tornou um dos principais veículos dos manifestos da entidade. A autora salienta que embora a CAMDE tenha nascido entre as mulheres de elite da Zona Sul carioca, isso não impediu que a entidade espalhasse seus núcleos até mesmo aos bairros pobres do Rio de Janeiro, como foi o caso da Rocinha, e em outros estados.

No ano de 1962 a CAMDE se envolveu profundamente nas eleições para a Câmara Federal e para parte do Senado. Sua intenção era alertar a população para a necessidade de votar em candidatos "democratas" para que os valores cristãos e da família estivessem resguardados. Assim, um dos principais alvos de combate da entidade era o petebista Leonel Brizola. Também naquele ano João Goulart propôs a antecipação do plebiscito parlamentar, isso levou as entidades femininas a se mobilizarem e enviar cerca de 60.000 
cartas ao Congresso pedindo a não-antecipação do plebiscito.

Todavia, foram nas Marchas da Família com Deus e pela Liberdade que a presença das mulheres foi mais importante. As marchas podem ser encaradas como uma reação à guinada para a esquerda do governo João Goulart, ocorrida emblematicamente no comício da Central do Brasil, no dia 13 de março. Neste comício, que reuniu cerca de 350.000 pessoas, discursaram importantes lideranças trabalhistas como Leonel Brizola e Miguel Arraes. As Reformas de Base ditaram o tom do discurso governista, mas João Goulart foi além e criticou duramente o uso reacionário de terços e rosários na luta contra as reformas. Segundo Janaina Cordeiro as palavras do presidente foi, possivelmente, uma resposta à atitude de um grupo de mulheres católicas que haviam impedido, com terços e rosários, o pronunciamento de Leonel Brizola em Belo Horizonte. (Cordeiro, 2009, p. 65). Isso levou as entidades femininas a encarar o ato do presidente como um desagravo ao rosário. Assim, no dia 19 de março, dia de São José, padroeiro da família, cerca de 500.000 pessoas saíram às ruas de São Paulo para protestar contra as intenções do governo em "comunizar o país". No Rio de Janeiro, como o golpe já havia sido desferido, a marcha teve um caráter comemorativo e reuniu cerca de um milhão de pessoas.

Passada a marcha, a CAMDE se empenhou na batalha pela indicação de Castello Branco à presidência e ao "saneamento" das estruturas de poder, ou seja, expurgar do governo qualquer resquício de trabalhismo ou comunismo. Logo após a posse de Castello Branco, as entidades femininas se uniram aos Diários Associados na campanha denominada "Ouro para o Bem do Brasil". Essa campanha visava arrecadar fundos ao governo para a obra de reconstrução do país, pois se acreditava que o país havia sido saqueado pelos comunistas infiltrados no governo.

A CAMDE através de telegrama apoiou incondicionalmente Castello Branco quando do decreto do AI-2, que estabelecia eleições indiretas para presidente e vicepresidente da república, a suspensão do direito de hábeas corpus e a extinção dos partidos políticos. O mesmo apoio foi dado a Costa e Silva quanto da instituição do AI-5.

No segundo capítulo, "a revolução autêntica, a tua mãe quem a fez: o público e o privado na militância política da CAMDE”, a autora busca discutir as intersecções entre o público e privado nas ações das mulheres da CAMDE. A maioria das mulheres que freqüentava tais entidades era católica e não tinha trabalho remunerado, ou seja, eram donas 
de casa. Ao se apresentarem como mães, esposas e donas de casa buscavam chamar atenção para o perigo da infiltração comunista que, na sua visão, procurava justamente fazer ruir instituições como a família, a Igreja e a pátria. Foi com o objetivo de salvar suas famílias que tais mulheres se lançaram ao espaço público, e como este tipo de mobilização visava a preservar um modelo tradicional de família, numa sociedade marcadamente patriarcal, essas mulheres tiveram o apoio de seus maridos.

Neste ponto, é importante situar as críticas da autora a uma linha interpretativa que privilegia o papel masculino na arregimentação das mulheres para a militância política conservadora. Janaína Cordeiro destaca a importância dos trabalhos de René Dreifuss e Solange de Deus Simões, mas indica seus limites, principalmente quando negam a autonomia das organizações femininas e afirmam a cooptação de tais entidades por organizações como o IPES (Instituto de Pesquisas e Estudos Sociais). Para a autora, é preciso "entender a participação política destas mulheres como uma opção consciente de militância conservadora em defesa de valores e instituições a partir das quais suas vidas eram organizadas" (Cordeiro, 2009, p. 118).

É importante salientar que foi Solange de Deus Simões uma das primeiras pesquisadoras a chamar a atenção para o fato de que esses grupos femininos inauguraram um novo estilo de atuação pública, uma vez que "elas se lançaram na esfera pública a partir da sua condição de seres privados”. (Simões, 1985, p. 10) Essas mulheres ao se apresentarem publicamente como mães e donas-de-casa não buscavam romper com o modelo patriarcal vigente, que perpetuava o domínio masculino na esfera pública, pois a sua luta era provisória e emergencial, deixavam o lar para se lançar às ruas e a praça pública para proteger os interesses da família, da moral, da propriedade, de Deus, da pátria. Oriundas da classe média, elas não procuravam romper com seu papel idealizado de mães e esposas, pelo contrário eram esses atributos que lhe conferiam a autoridade e a legitimidade para atuar e fazer sentir sua presença na esfera política. Não havia a compreensão do comunismo como um sistema político, ele era encarado como uma "doutrina", cujo principal objetivo seria o de "subverter a moral, eliminar a religião e separar os pais dos filhos". (Simões, 1985, p. 85).

No terceiro e último capítulo, "A CAMDE entre memória e história”, a autora buscou analisar as construções da memória empreendidas pelas militantes da CAMDE. 
Nesta empresa levantou 105 nomes, desse total 15 já haviam falecidas e 73 não foram encontradas, das 17 restantes somente quatro se dispuseram a falar, ainda que em grupo e sob a condição de anonimato. Tais memórias são marcadas por silêncios, esquecimentos, decepções com os caminhos que tomou a "Revolução", por um medo de seus posicionamentos no passado tornarem-se incompreensíveis no presente.

Uma das principais dificuldades diz respeito ao fato de rememorar a história de uma entidade que participou ativamente da construção do regime militar. Neste sentido, a memória do grupo é permeada pelo silêncio. Afinal, em tempos de celebração da democracia torna-se inconveniente lembrar-se de uma história de oposição a um governo democraticamente eleito e do apoio a governos que fecharam todos os canais de participação democrática.

Embora as militantes afirmem que depois da "Revolução" não houvesse mais razão para o grupo existir, há evidências que indicam seu consentimento em relação às medidas adotadas pelo governo militar, principalmente os Atos Institucionais $n^{\circ} 2$ e 5 . No entanto, foi durante os anos finais do endurecimento do regime, em 1974 sob Médici, que a entidade se desfez.

Ao concluir que "recuperar a trajetória de grupos como a CAMDE possibilita compreender que a manutenção da ditadura por 21 anos vai além dos militares", a autora também aponta um aspecto importante da história da ditadura, o papel de parcelas importantes da sociedade na legitimação e manutenção do regime autoritário (Cordeiro, 2009, p. 193). Obviamente, não se pode creditar a manutenção da ditadura apenas ao apoio de determinados grupos sociais. Todavia, não devemos nos furtar da observação de que alguns grupos, como as entidades femininas conservadoras, eram sustentáculos importantes do regime.

O trabalho de Janaína Martins Cordeiro certamente traz uma contribuição inovadora para a historiografia do regime militar. Ao optar por questionar as construções e reconstruções de memória traz questões muito relevantes para o debate histórico. Uma vez que, não foram somente os grupos de direita que tiveram que readequar seus discursos ao ambiente democrático, as esquerdas também buscaram qualificar sua resistência ao regime como uma resistência democrática.

Por outro lado, a autora não buscou instituir um tribunal da história, pelo contrário, 
tentou compreender a colaboração das organizações femininas ao regime pelas contingências do próprio contexto. Afinal, essas mulheres de elite e classe média somente se lançaram à esfera pública com terços e rosários na mão por que acreditavam que seu mundo estava realmente em perigo, que o comunismo ameaçava ruir o que para elas era mais sagrado, a saber: os valores cristãos, a família e a pátria.

\section{Referências bibliográficas}

CORDEIRO, Janaína Martins. Direitas em movimento: a Campanha da Mulher pela Democracia e a ditadura no Brasil. Rio de Janeiro: Editora FGV, 2009.

DREIFUSS, René. Armand. 1964: a conquista do Estado. Petrópolis: Vozes, 1981

RIDENTI, Marcelo. Resistência e mistificação da resistência armada contra a ditadura: armadilhas para os pesquisadores. In: REIS. Daniel Aarão; RIDENTI, Marcelo e MOTTA, Rodrigo Patto Sá. O golpe e a ditadura militar 40 anos depois (1964-2004). Bauru: EDUSC, 2004.

SIMÕES, Solange de Deus. Deus, pátria e família. As mulheres no Golpe de 1964. Petrópolis: Vozes, 1985. 